\title{
Original ADJUVANT INFUSIONAL FLUOROURACIL AND LEUCOVORIN WITH OR Article WITHOUT OXALIPLATIN IN TREATMENT OF STAGE II AND III COLON CANCER
}

\author{
Niveen Abo-Touk ${ }^{1}$, Mohamed Elashery ${ }^{1}$, Eman Elzahaf ${ }^{1}$, Mona Fouda and Thrwat \\ Kandil $^{2}$
}

${ }^{1}$ Clinical Oncology and Nuclear Medicine, ${ }^{2}$ Gastro-entrology, Faculty of Medicine, Mansoura University, Egypt.

\begin{abstract}
Introduction: Fluorouracil and leucovorin has been accepted as the standard adjuvant therapy in colon cancer for many years. The aim is to demonstrate the benefit from addition of oxaliplatin to infusional fluorouracil plus leucovorin as adjuvant therapy for stage III and high risk stage II colon cancer.

Patients and Methods: From April 2005 to Marsh 2006, 100 patients who had undergone curative surgery for colon cancer, stage III or high risk stage II disease, were randomized to receive either 2-hour intravenous infusion of $200 \mathrm{mg} /$ $\mathrm{m}^{2}$ of leucovorin followed by bolus of $400 \mathrm{mg} / \mathrm{m}^{2}$ of fluorouracil and then 22-hour infusion of $600 \mathrm{mg} / \mathrm{m}^{2}$ of fluorouracil on 2 consecutive days every 14 days, for 12 cycles (50 patients) or receive the same regimen with oxaliplatin, $85 \mathrm{mg} /$ $\mathrm{m}^{2}$ as two-hour infusion concurrent with leucovorin on day 1(50 patients).

Results: Eight patients in the group received oxaliplatin (16.7\%) had relapsed as compared with 18 patients (36\%) in the group received fluorouracil plus leucovorin without oxaliplatin, the difference was statistically significant $(\mathrm{P}=0.03)$. The disease-free survival was higher in the group of patients received oxaliplatin than in the Group of patients received fluorouracil plus leucovorin without oxaliplatin, $(\mathrm{P}=0.03)$. Overall survival was not statistically different between the two groups $(\mathrm{P}=0.14)$. The incidence of neutropenia and neurosensory symptoms were statistically significantly higher with oxaliplatin.

Conclusions: Patients with stage III and high-risk stage II colon cancer obtain benefit from the addition of oxaliplatin to infusional fluorouracil plus leucovorin.
\end{abstract}

Key Words: Colon cancer, adjuvant therapy, chemotherapy, oxaliplatin

Corresponding Author: Mona Fouda, Tel.: 0123948580, Fax: 0235840732, E-mail: monamfoda@yahoo.com

\section{INTRODUCTION}

Worldwide, colorectal cancer (CRC) represents a public health problem accounting for over 1 million cases of new cancers and about half a million deaths in $2002^{1}$. It is the third most common noncutaneous malignant disease in the United States, with 153,760 new cases and 52,180 deaths anticipated in $2007^{2}$. In USA colorectal cancer constitutes $9.5 \%$ of all cancers, whereas, in Egypt it contributes $6.5 \%$ of all cancers ${ }^{3}$. Despite curative surgery in those presenting early, the risk of recurrence is significantly high. Hence much work has been done in search of an effective adjuvant therapy for the eradication of micro-metastases ${ }^{4}$.

There is clear evidence that adjuvant chemotherapy has a beneficial effect on tumor relapse and overall survival in patients with a curatively resected stage III colon carcinoma. Adjuvant therapy with 5-fluorouracil (5-FU)/ levamisole for 12 months (Moertel scheme) reduced the risk of cancer recurrence by $41 \%$ and the overall death rate by $33 \%$ after more than 5 years of follow-up ${ }^{5}$. Results of the adjCCA-01 trial demonstrated that adjuvant treatment with 5-FU plus leucovorin was significantly more effective than 5-FU/ levamisole (Moertel scheme) in reducing tumor relapse and improving survival ${ }^{6}$. In addition, no administration schedule of fluorouracil was found to be superior to any other in the adjuvant setting ${ }^{7}$.

It has been proposed that adjuvant chemotherapy may benefit patients with stage II disease with T4 tumor stage, bowel perforation, or clinical bowel obstruction ${ }^{8}$. Other high-risk features, such as inadequate lymph node sampling, lymphovascular or perineural invasion, poorly differentiated histology, microsatellite instability and loss of heterozygosity at chromosome $18 \mathrm{q}$, are also known to carry a higher risk of recurrence ${ }^{9}$.

The major side effects associated with fluorouracil depend on the method of administration. Neutropenia and stomatitis were the most frequent side effects when bolus fluorouracil and leucovorin were administered daily for 5 days every 4 to 5 weeks (the "Mayo Clinic regimen"), with mild alopecia and vomiting also commonly observed. Higher rates of debilitating diarrhea resulted when bolus fluorouracil and leucovorin were 
administered weekly for 6 of 8 weeks (the "Roswell Park regimen"). Schedules that administered fluorouracil as a continuous infusion were associated with less hematologic and gastrointestinal toxicity, but with the appearance of hand-foot syndrome ${ }^{10}$.

Oxaliplatin is a diaminocyclohexane platinum compound that forms DNA adducts, leading to impaired DNA replication and cellular apoptosis. In preclinical testing, oxaliplatin was shown to be active as a single agent and synergistic when combined with fluorouracil in colorectal cancer cell lines, possibly due to oxaliplatininduced down-regulation of thymidylate synthetase ${ }^{11}$. In patients with metastatic colon cancer, oxaliplatin has clinical benefit when it is administered with infusional fluorouracil and leucovorin, a treatment regimen known as FOLFOX $4^{12}$. Randomized clinical trials have consistently shown that FOLFOX4 results in response rates and times to disease progression that are superior to those achieved with fluorouracil and leucovorin in treatment of advanced colorectal cancer ${ }^{13}$.

In the Multicenter International Study of Oxaliplatin/ Fluorouracil/Leucovorin in the Adjuvant Treatment of Colon Cancer (MOSAIC) study 2,246 patients with Stage II $(40 \%)$ or Stage III $(60 \%)$ colon cancer were randomized to receive 6 months of infusional fluorouracil and leucovorin with or without oxaliplatin (FOLFOX4). The FOLFOX-treated cohort had a greater likelihood of remaining free of recurrence after four years. This difference was far more evident among patients with stage III disease than among those with stage II disease. FOLFOX treatment has not yet been found to confer a statistically significant advantage in terms of overall survival $^{14,15 .}$

The objective of this study was to study the value of addition of oxaliplatin to infusional fluorouracil plus leucovorin as adjuvant therapy for stage III and high risk stage II colon cancer.

\section{PATIENTS AND METHODS}

From April 2005 to Marsh 2006, 100 eligible patients with colon cancer were included in this study.

\section{Eligibility criteria:}

Patients enrolled in this trial required to meet the following eligibility criteria: Patients were between 18 and 70 years old with histologically confirmed invasive adenocarcinoma of the colon without gross or microscopic evidence of residual disease after curative resection, stage III (Dukes' stage C) or stage II disease (Dukes' stage B) with T4 tumor stage, bowel perforation, clinical bowel obstruction, inadequate lymph node sampling less than 12 lymph nodes, lymphovascular or perineural invasion, or poorly differentiated histology. Patients were fully recovered within 8 weeks before random assignment and they had to be ambulatory with an Eastern Cooperative
Oncology Group performance status score of 0 or 1 .

Other eligibility criteria included adequate baseline bone marrow function (white blood cell [WBC] count of at least $4000 / \mu 1$ and $<12000 / \mu 1$, neutrophil count $>2000 /$ $\mu 1$ and platelet count $>100000 / \mu 1$ ), adequate hepatic and renal function. Patients consent and approval of ethical committee were obtained.

\section{Exclusion criteria:}

Patients were excluded on basis of prior chemotherapy or radiotherapy, evidence of metastatic disease, clinical significant cardiac disease, serious medical illness or patients refusal.

\section{Pretreatment evaluation:}

Before enrollment, patient demographics, medical history, prior cancerand treatment history and concomitant diseases/ treatment were assessed at this time. All patients underwent a physical examination. Eastern Cooperative Oncology Group performance status, as well as laboratory investigations including complete blood cell count with differential count, liver and renal function tests and carcino-embryonic antigen determination were assessed. Chest radiography, electrocardiography and abdomeno-pelvic computed tomographic (CT) scanning or magnetic resonance imaging (MRI) were done. Either barium enema or endoscopy before therapy was done if needed. Complete wound healing was mandatory.

\section{Treatment plan:}

Patients were randomized to receive adjuvant treatment with fluorouracil and leucovorin either with oxaliplatin (50 patients) or without oxaliplatin (50 patients). Randomization was done through the closed envelop method. All patients received 2-hour intravenous infusion of $200 \mathrm{mg} / \mathrm{m}^{2}$ of leucovorin followed by a bolus of $400 \mathrm{mg} / \mathrm{m}^{2}$ of fluorouracil and then a 22-hour infusion of $600 \mathrm{mg} / \mathrm{m}^{2}$ of fluorouracil given on 2 consecutive days every 14 days, for 12 cycles. In the Group given oxaliplatin, $85 \mathrm{mg} / \mathrm{m}^{2}$ of oxaliplatin was diluted with 250 $\mathrm{ml}$ of $5 \%$ glucose solution and administered as two-hour infusion concurrent with leucovorin on day 1, the same leucovorin and fluorouracil regimen was used. All patients received premedication with a 5-hydroxytryptamine3-receptor antagonist with or without dexamethasone, given as a 30 min drip infusion before chemotherapy.

During the study, complete blood cell counts including differential count; liver function tests and serum creatinine were performed every 2 weeks. Toxicities were assessed according to the National Cancer Institute Common Toxicity Criteria, Version 2.0 (NCI-CTC). If the WBC count was $<3000 / \mu 1$, the neutrophil count $<1500 /$ $\mu 1$, or the platelet count $<75000 / \mu 1$, further treatment was delayed until recovery.

Dose-limiting toxicity (DLT) was defined as any of the following findings during treatment; a neutrophil 
count of $<500 / \mu 1$, grade 3 febrile neutropenia, a platelet count of $<50000 / \mu 1$, grade 3 or 4 non-hematologic toxicity, excluding nausea and anorexia, according to the NCI-CTC, or a longer than 1 week delay in treatment as a result of drug-related toxicity. If DLT occurred, dose reductions were based on the worst adverse effects observed during the previous cycle. The subsequent dose of oxaliplatin was to be reduced to $75 \%$ of the initial dose, if temporary painful paresthesias occured. Oxaliplatin was discontinued in cases of persistent painful paresthesias, functional impairment or grade 3 or 4 allergic reactions. Fluorouracil was also reduced to $75 \%$ of the doses in case of grade 3 or 4 neutropenia or thrombocytopenia (or both), diarrhea, stomatitis, cutaneous or other drug-related adverse effects of grade 3 or 4 . Recombinant granulocyte colony-stimulating factor was subcutaneously injected if patients had grade 4 neutropenia or grade 3 febrile neutropenia, but prophylactic use was not allowed.

\section{Follow-up:}

Physical examination and blood chemistries, were performed every cycle. Specific adverse events were listed and graded according to the Common Toxicity Criteria of the National Cancer Institute (Version 2) throughout the treatment period. Measurement of the carcino-embryonic antigen level, chest radiography, abdominal magnetic resonance imaging or computed tomography were done postoperative and every six months to identify the presence of disease recurrence. If necessary, barium study, colonoscopy and cytological analysis or biopsy were performed to confirm diagnoses of relapse. Disease-free survival (DFS), was defined as the time from random assignment to the earliest time of recurrence in local, regional, or distant sites; second primary colon cancer; or death from any cause. Overall survival, defined as time to death (including deaths with or without recurrence).

\section{Statistical Analysis}

The statistical analysis of data done by using SPSS program (statistical package for social science version 13). The analysis of the data was done to test statistical significant difference between groups. For quantitative date, student $t$-test was used to compare between 2 groups. Survival analysis and disease free survival were done by Kaplan Meier curve with the use of log- rank test.

N.B: $\mathrm{P}$ is significant if $<$ or $=0.05$ at confidence interval $95 \%$.

\section{RESULTS}

After randomization 2 patients were delayed in treatment due to unavailable oxaliplatin and they were excluded from our study. All patients received infusional fluorouracil plus leucovorin while oxaliplatin was added in only 48 patients. Pretreatment characteristics were similar in the two treatment groups and were summarized in Table (1).
Table 1: Baseline characteristics of the patients.

\begin{tabular}{|c|c|c|c|c|}
\hline \multirow[t]{2}{*}{ Characteristics } & \multicolumn{2}{|c|}{$\begin{array}{l}\text { Oxaliplatin, } \\
\text { fluorouracil } \\
\text { plus leucovorin }\end{array}$} & \multicolumn{2}{|c|}{$\begin{array}{l}\text { fluorouracil plus } \\
\text { leucovorin }\end{array}$} \\
\hline & $\mathrm{N}=48$ & $\%$ & $\mathrm{~N}=50$ & $\%$ \\
\hline $\begin{array}{l}\text { Age } \\
\text { median(range) }\end{array}$ & 47 & $\begin{array}{l}(22- \\
69)\end{array}$ & 45 & $(23-70)$ \\
\hline \multicolumn{5}{|l|}{ Sex } \\
\hline Male & 25 & 52.1 & 27 & 54 \\
\hline Female & 23 & 47.9 & 23 & 46 \\
\hline \multicolumn{5}{|l|}{$\begin{array}{l}\text { Performance } \\
\text { status }\end{array}$} \\
\hline 0 & 41 & 85.4 & 44 & 88 \\
\hline 1 & 7 & 14.6 & 6 & 12 \\
\hline \multicolumn{5}{|l|}{ Tumor grade } \\
\hline I & 8 & 16.7 & 7 & 14 \\
\hline$\Pi$ & 27 & 56.3 & 30 & 60 \\
\hline Ш & 9 & 18.7 & 10 & 20 \\
\hline Unknown & 4 & 8.3 & 3 & 6 \\
\hline \multicolumn{5}{|l|}{ Tumor stage } \\
\hline$\Pi$ & 16 & 33.3 & 17 & 34 \\
\hline Ш & 32 & 66.7 & 33 & 66 \\
\hline \multicolumn{5}{|l|}{ Wall invasion } \\
\hline $\mathrm{T} 2$ & 3 & 6.3 & 4 & 8 \\
\hline $\mathrm{T} 3$ & 36 & 75 & 38 & 76 \\
\hline $\mathrm{T} 4$ & 9 & 18.7 & 8 & 16 \\
\hline \multicolumn{5}{|l|}{ Nodal status } \\
\hline No & 16 & 33.3 & 17 & 34 \\
\hline $\mathrm{N} 1$ & 22 & 45.9 & 24 & 48 \\
\hline $\mathrm{N} 2$ & 10 & 20.8 & 9 & 18 \\
\hline \multicolumn{5}{|l|}{$\begin{array}{l}\text { Number of } \\
\text { dissected LN }\end{array}$} \\
\hline$<12$ & 31 & 64.6 & 30 & 60 \\
\hline$\geq 12$ & 17 & 35.4 & 20 & 40 \\
\hline $\begin{array}{l}\text { Bowel } \\
\text { obstruction }\end{array}$ & 8 & 16.7 & 9 & 18 \\
\hline Perforation & 4 & 8.3 & 3 & 6 \\
\hline
\end{tabular}

Eighty one percent of patients in oxaliplatin with fluorouracil plus leucovorin group and 89 percent in fluorouracil plus leucovorin group completed treatment as planned. Eight patients $(16.7 \%)$ in the group received fluorouracil plus leucovorin with oxaliplatin had relapsed as compared with 18 patients (36\%) in group received fluorouracil plus leucovorin without oxaliplatin. The hazard ratio for relapse in the group received oxaliplatin as compared with the other group, was 0.36 (95\% confidence interval, 0.14 to $0.92 ; \mathrm{P}=0.03$ ), this result was statistically significant. As regard total number of deaths 8 patients $(16.7 \%)$ had died in the group of patients given fluorouracil plus leucovorin with oxaliplatin as compared with 13 patients $(26 \%)$ in group of patients given fluorouracil plus leucovorin without oxaliplatin. The hazard ratio for death was 0.57 (95\% confidence 
interval, 0.21 to $1.53 ; \mathrm{P}=0.26$ ), this result was statistically insignificant Table (2).

Table 2: Incidence of treatment failure.

\begin{tabular}{|c|c|c|c|c|c|c|}
\hline \multirow[t]{2}{*}{ Events } & \multicolumn{3}{|c|}{$\begin{array}{l}\text { Oxaliplatin, } \\
\text { Fluorouracil } \\
\text { plus } \\
\text { leucovorin } \\
\qquad(\mathrm{N}=48)\end{array}$} & \multicolumn{2}{|c|}{$\begin{array}{l}\text { Fluorouracil } \\
\text { plus } \\
\text { leucovorin }\end{array}$} & P-value \\
\hline & $\mathbf{N}$ & $\mathbf{0}$ & $\%$ & No & $\%$ & $\mathbf{P}$ \\
\hline Local recurrence & 2 & & 4.2 & 5 & 10 & 0.44 \\
\hline Distant metastases & 5 & & 10.4 & 11 & 22 & 0.12 \\
\hline $\begin{array}{l}\text { Second colorectal } \\
\text { carcinoma }\end{array}$ & 1 & & $2 \cdot 1$ & 2 & 4 & 0.58 \\
\hline relapse & 8 & & 16.7 & 18 & 36 & $0.03 *$ \\
\hline $\begin{array}{l}\text { Death without } \\
\text { relapse }\end{array}$ & 1 & & 2.1 & 1 & 2 & \\
\hline $\begin{array}{l}\text { Total number of } \\
\text { deaths }\end{array}$ & 8 & & 16.7 & 13 & 26 & 0.26 \\
\hline
\end{tabular}

$*=$ Statistically significant difference

Grades 3 and 4 neutropenia and neurosensory symptoms were higher in group of patients received fluorouracil plus leucovorin with oxaliplatin than in group of patients received fluorouracil plus leucovorin without oxaliplatin, the differences were statistically significant. The incidence of thrombocytopenia, anemia and diarrhea were higher in patients given oxaliplatin but grade 3 or 4 events were statistically insignificant Table (3).

Table 3: Grades 3 and 4 toxicity during treatment.

\begin{tabular}{llllll}
\hline Adverse events & $\begin{array}{c}\text { Oxaliplatin } \\
\text { with } \\
\text { fluorouracil } \\
\text { plus } \\
\text { leucovorin } \\
\text { (N=48) }\end{array}$ & $\begin{array}{c}\text { Fluorouracil } \\
\text { plus } \\
\text { leucovorin } \\
\text { (N=50) }\end{array}$ & P-value \\
\cline { 2 - 5 } & No & \% & No & \% & \\
\hline Neurosensory & 5 & 10.4 & 0 & 0 & $0.02^{*}$ \\
Neutropenia & 19 & 39.6 & 3 & 6 & $0.001 *<$ \\
Thrombocytopenia & 1 & 2.1 & 0 & 0 & 0.31 \\
Anemia & 1 & 2.1 & 1 & 2 & 0.98 \\
Diarrhea & 4 & 8.3 & 3 & 6 & 0.37 \\
Stomatitis & 1 & 2.1 & 1 & 2 & 0.98 \\
Nausea & 3 & 6.3 & 1 & 2 & 0.29 \\
Vomiting & 4 & 8.3 & 1 & 2 & 0.15 \\
Hand-foot syndrom & 1 & 2.1 & 1 & 2 & 0.98 \\
\hline
\end{tabular}

* = Statistically significant difference.

Disease-free survival washigherin the group ofpatients received fluorouracil plus leucovorin with oxaliplatin than in the group of patients received fluorouracil plus leucovorin without oxaliplatin, $(\mathrm{P}=0.03)$ (Fig.1). On the analysis of patients with high risk stage II colon cancer the hazard ratio for recurrence in the group given oxaliplatin, as compared with group of patients given fluorouracil without oxaliplatin was 0.12 (95 percent confidence interval, $0.01-1.17 ; \mathrm{P}=0.04)$. The difference in risk of recurrence between patients with stage II and stage III was insignificant in group of patients received oxaliplatin $(p=0.17)$. The disease -free survival for both high risk stage II and stage III patients were higher in the group given oxaliplatin, as compared with the group given fluorouracil without oxaliplatin, the differences were statistically significant (Figs. 2,3). Although the overall survival was higher in the group of patients received fluorouracil plus leucovorin with oxaliplatin than in the group of patients received fluorouracil plus leucovorin without oxaliplatin, the difference was not statistically significant $(\mathrm{P}=0.14)$ (Fig. 4). The mean follow- up time was 30 months, with range (5-44) months and the median follow- up was 33.5 months.

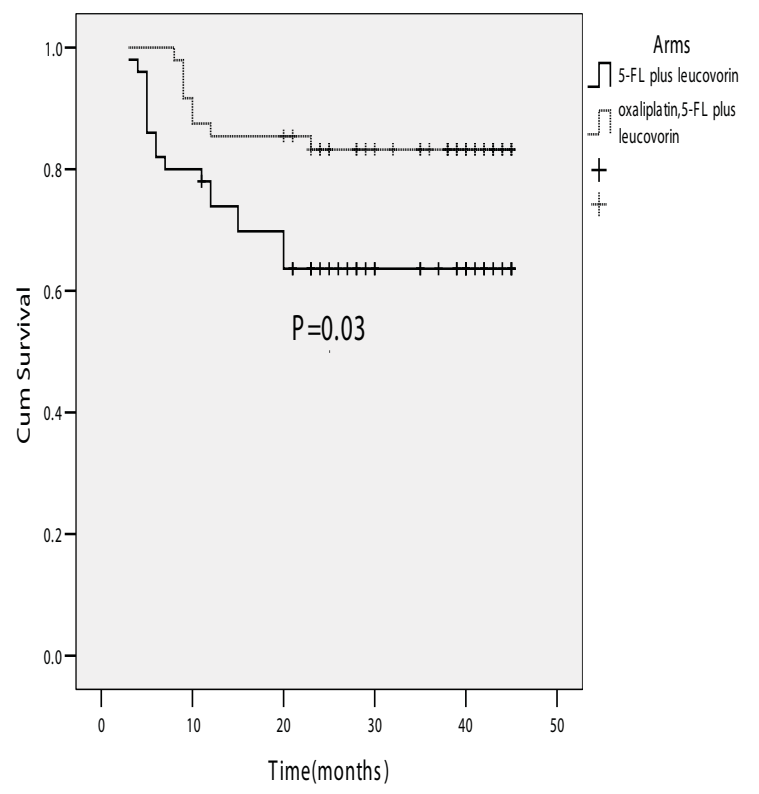

Fig. 1: Disease-free survival.

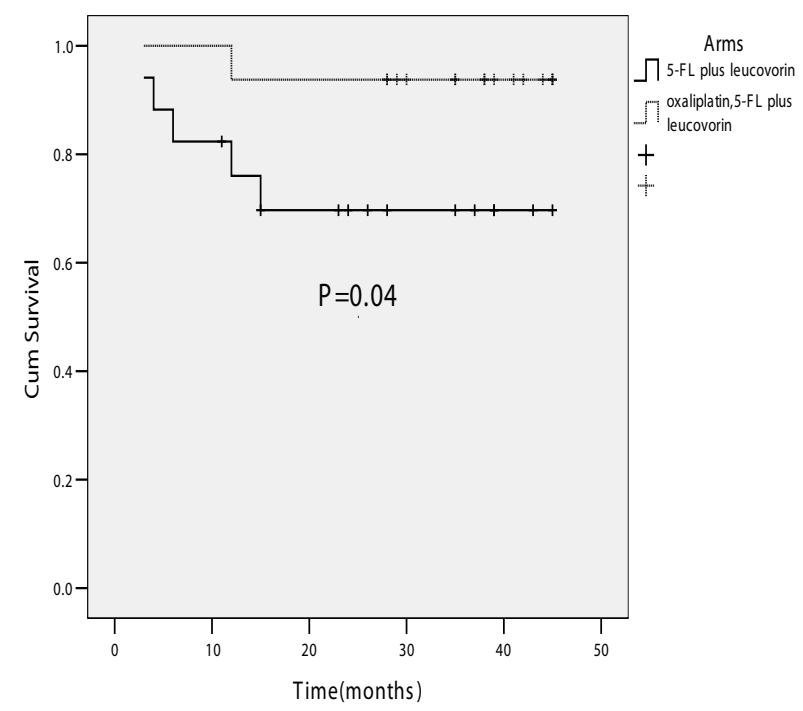

Fig. 2: Disease-free survival for high-risk stage II. 


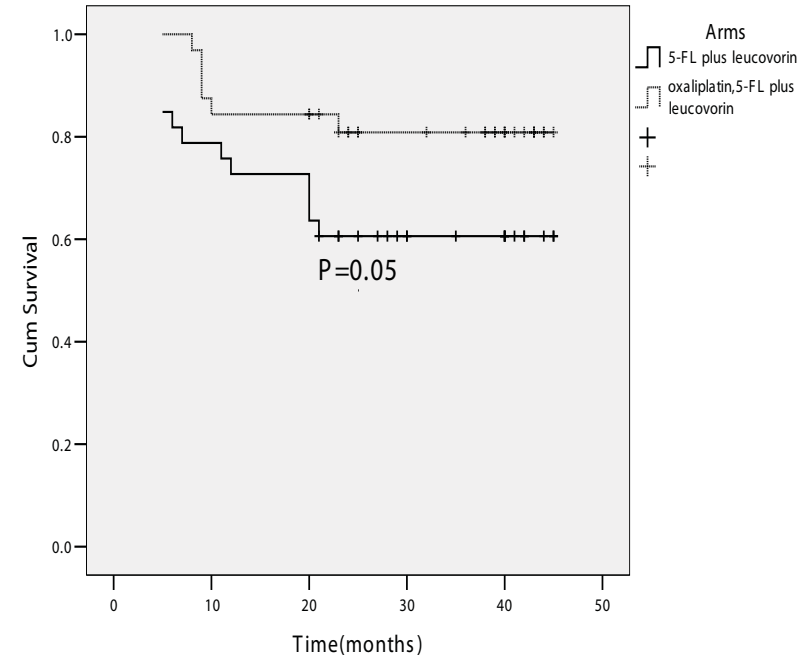

Fig.3: Disease-free survival for stage III

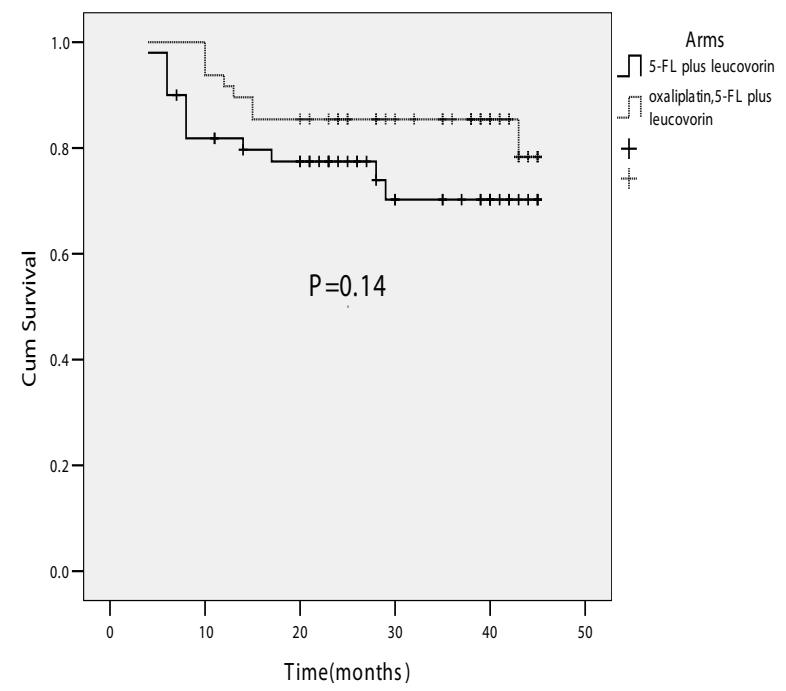

Fig. 4: Overall survival

\section{DISCUSSION}

For patients with stage III colon cancer, an overall survival benefit for fluorouracil-based chemotherapy has been firmly established ${ }^{16}$. For patients with stage II colon cancer, the use of adjuvant chemotherapy remains controversial, but may be appropriate in a subset of individuals at high risk for disease recurrence ${ }^{17}$. Six months of fluorouracil (5-FU) and leucovorin(LV) following resection of stage III colon cancer has become standard adjuvant therapy, credited with an estimated onethird reduction in the risk of colon cancer recurrence ${ }^{18}$.

The 5-FU/LV-oxaliplatin combination seems beneficial as first-line therapy in advanced colorectal cancer, demonstrating a significantly improved response rate, prolonged progression-free survival with acceptable tolerability and maintenance of quality of life ${ }^{19}$.

Oxaliplatin has been further examined as adjuvant therapy for colon cancer to verify whether it can improve survival in this setting. The result of the present study showed that group of patients received fluorouracil plus leucovorin with oxaliplatin had statistically significant lower incidence of recurrence than group of patients received fluorouracil plus leucovorin without oxaliplatin. This is associated with improvement in disease-free survival (DFS). This result coincided with results reported in the two large trials MOSAIC and NSABPC $07^{20,21}$. The addition of oxaliplatin to 5-fluorouracil, leucovorin as adjuvant therapy after surgery for patients with stage II and III colon cancer has been shown to prolong DFS significantly with reduction in the risk of recurrence compared with 5-fluorouracil and leucovorin. However there was no statistical difference in overall survival.

In our trial the difference in the risk of recurrence between stage II and stage III patients was insignificant in the group of patients received oxaliplatin, whereas patients with stage II constituted $(33.3 \%)$ of the included patients and stage III patients constituted (66.7\%). In agreement with both MOSAIC and NSABPC 07 trials ${ }^{20,21}$, no significant interactions between stages (stage II and III) and treatment effect were seen in either study ${ }^{22}$. However, in our study stage II patients were selected high risk patients and that was not considered in both trials.

On analysis of patients with stage II colon cancer in our study the risk for recurrence in the group given oxaliplatin, was lower than in patients given fluorouracil without oxaliplatin, the difference was statistically significant $(\mathrm{P}=0.04)$. On the basis of the MOSAIC results, adjuvant therapy for stage II patients with FOLFOX provides an improvement of DFS compared with optimized (infusional) 5-Fluorouracil / Leucovorin therapy ${ }^{23}$. The CCOPGI Gastrointestinal Cancer Disease Site Group, also demonstrated that adjuvant therapy was associated with a small absolute improvement in disease-free survival (ranging from 5\% to 10\%), but this did not translate into a statistically significant difference in overall survival. The CCOPGI guideline concluded that there was no clear evidence to routinely recommend adjuvant therapy for stage II patients ${ }^{24}$.

A retrospective subset analysis of four consecutive National Surgical Adjuvant Breast and Bowel Project (NSABP) trials noted a similar proportional survival benefit for Stage II and Stage III patients who received fluorouracil-based therapy, leading the authors to recommend adjuvant treatment for patients with both Stage II and III colon cancer ${ }^{25}$. Whereas, the International Multicenter Pooled Analysis of Colon Cancer Trials B2 study (IMPACT) combined data from five randomized trials had failed to show a statistically significant benefit of adjuvant fluorouracil with leucovorin when compared with surgery alone in the subsets of patients with stage II disease. The 5-year overall survival estimates were not statistically different for the stage II patients ${ }^{26}$.

As regard total death in our study, 8 patients had died in the group of patients given fluorouracil plus 
leucovorin with oxaliplatin (16.7\%) as compared with 13 patients $(26 \%)$ in the group of patients given fluorouracil plus leucovorin without oxaliplatin. Overall survival was higher in the group of patients received fluorouracil plus leucovorin with oxaliplatin than in group of patients received fluorouracil plus leucovorin without oxaliplatin but the difference was not statistically significant. However, a strong correlation of DFS at 3 or 4 years with the traditional end point of 5-year survival for colon cancer adjuvant therapy has been shown in a pooled analysis of 20,898 patients participating in randomized clinical trials $^{27}$. For trials in patients with stage III disease, or a mix of stage II and III disease, DFS after 3-year median follow-up is a valid and appropriate primary end point. For trials in the stage II-only population, at this time OS remains an appropriate primary end point ${ }^{28}$. Final DFS in patients of the MOSAIC trial, at 5 years follow up, are consistent with earlier results. In addition, at a median follow up of 6 years, the study demonstrates a significant benefit in OS for the stage III patients. Long-term safety update shows no increase in the rate of secondary cancer $^{29}$.

Among patients who were assigned to receive oxaliplatin grade 3 or 4 neutropenia and neurosensory symptoms were statistically significant higher. The incidence of thrombocytopenia, anemia, hand-foot syndrome and diarrhea were higher in patients given oxaliplatin but grade 3 or 4 events were statistically insignificant. These results were consistent with results of MOSAIC study, however, the incidence of thrombocytopenia, and diarrhea were statistically significant higher with oxaliplatin ${ }^{14}$. Whereas, in first line treatment, patients received oxaliplatin developed grade 3/4 neutropenia, diarrhea, mucositis and neuropathy more frequent but thrombocytopenia, anemia were insignificant. The incidences and severities of skin toxicity remained particularly low ${ }^{19}$.

\section{CONCLUSION}

Infusional fluorouracil plus leucovorin with oxaliplatin is beneficial in improving disease free survival as adjuvant therapy after surgery for patients with stage III colon cancer. Stage II patients with any number of poor prognostic features such as T4 lesion, inadequate lymph node dissection, perforation, intestinal obstruction or poorly differentiated histology, might also be considered as candidates for this adjuvant chemotherapy.

\section{REFERENCES}

1. Parkin DM, Bray F, Ferlay J, Pisani P. Global cancer statistics, 2002. CA Cancer.J.Clin. 2005 Mar-Apr;55(2):74-108.

2. Jemal A, Siegel R, Ward E, Murray T, Xu J, Thun MJ. Cancer statistics, 2007. CA Cancer J.Clin. 2007 Jan-Feb;57(1):43-66.

3. El Bolkainy MN, Nouh MA, El Bolkainy T. Topographic pathology of cancer. 3rd ed. Cairo University: National Cancer Institute; 2005.
4. Chau I, Cunningham D. Adjuvant therapy in colon cancer--what, when and how? Ann.Oncol. 2006 Sep;17(9):1347-59.

5. Moertel CG, Fleming TR, Macdonald JS, Haller DG, Laurie JA, Tangen CM, et al. Fluorouracil plus levamisole as effective adjuvant therapy after resection of stage III colon carcinoma: A final report. Ann.Intern.Med. 1995 Mar 1;122(5):321-6.

6. Porschen R, Bermann A, Loffler T, Haack G, Rettig K, Anger Y, et al. Fluorouracil plus leucovorin as effective adjuvant chemotherapy in curatively resected stage III colon cancer: Results of the trial adjCCA-01. J.Clin.Oncol. 2001 Mar 15;19(6):1787-94.

7. Andre T, Colin P, Louvet C, Gamelin E, Bouche O, Achille E, et al. Semimonthly versus monthly regimen of fluorouracil and leucovorin administered for 24 or 36 weeks as adjuvant therapy in stage II and III colon cancer: Results of a randomized trial. J.Clin. Oncol. 2003 Aug 1;21(15):2896-903.

8. Benson AB, Schrag D, Somerfield MR, Cohen AM, Figueredo AT, Flynn PJ, et al. American Society of Clinical Oncology recommendations on adjuvant chemotherapy for stage II colon cancer. J.Clin.Oncol. 2004 Aug 15;22(16):3408-19.

9. Compton C, Fenoglio Preiser CM, Pettigrew N, Fielding LP. American Joint Committee on Cancer Prognostic Factors Consensus Conference: Colorectal Working Group. Cancer 2000 Apr 1;88(7):1739-57.

10. De Gramont A, Bosset JF, Milan C, Rougier P, Bouche O, Etienne PL, et al. Randomized trial comparing monthly lowdose leucovorin and fluorouracil bolus with bimonthly high-dose leucovorin and fluorouracil bolus plus continuous infusion for advanced colorectal cancer: A French intergroup study. J.Clin. Oncol. 1997 Feb;15(2):808-15.

11. Raymond E, Faivre S, Chaney S, Woynarowski J, Cvitkovic E. Cellular and molecular pharmacology of oxaliplatin. Mol.Cancer. Ther. 2002 Jan;1(3):227-35.

12. Rothenberg ML, Oza AM, Bigelow RH, Berlin JD, Marshall JL, Ramanathan RK, et al. Superiority of oxaliplatin and fluorouracilleucovorin compared with either therapy alone in patients with progressive colorectal cancer after irinotecan and fluorouracilleucovorin: Interim results of a phase III trial. J.Clin.Oncol. 2003 Jun 1;21(11):2059-69.

13. Giacchetti S, Perpoint B, Zidani R, Le Bail N, Faggiuolo R, Focan $\mathrm{C}$, et al. Phase III multicenter randomized trial of oxaliplatin added to chronomodulated fluorouracil-leucovorin as first-line treatment of metastatic colorectal cancer. J.Clin.Oncol. 2000 Jan;18(1):136-47.

14. Andre T, Boni C, Mounedji Boudiaf L, Navarro M, Tabernero J, Hickish T, et al. Oxaliplatin, fluorouracil and leucovorin as adjuvant treatment for colon cancer. N.Engl.J.Med. 2004 Jun 3;350(23):2343-51.

15. De Gramont A, Boni C, Navarro M, et al. Oxaliplatin/5FU/LV in the adjuvant treatment of stage II and stage III colon cancer: Efficacy results with a median follow-up of 4 years. J.Clin.Oncol. 2005;23:16S (Abstr 3501).

16. Gill S, Loprinzi CL, Sargent DJ, Thome SD, Alberts SR, Haller DG, et al. Pooled analysis of fluorouracil-based adjuvant therapy for stage II and III colon cancer: Who benefits and by how much? J.Clin.Oncol. 2004 May 15;22(10):1797-806.

17. Wolpin BM, Meyerhardt JA, Mamon HJ, Mayer RJ. Adjuvant treatment of colorectal cancer. CA Cancer.J.Clin. 2007 MayJun;57(3):168-85.

18. Macdonald JS. Adjuvant therapy of colon cancer. CA 
Cancer.J.Clin. 1999 Jul-Aug;49(4):202-19.

19. De Gramont A, Figer A, Seymour M, Homerin M, Hmissi A, Cassidy J, et al. Leucovorin and fluorouracil with or without oxaliplatin as first-line treatment in advanced colorectal cancer. J.Clin.Oncol. 2000 Aug;18(16):2938-47.

20. De Gramont A, Vanzi N, Navarro M, et al. Oxaliplatin/5-FU/LV in adjuvant colon cancer: Results of the International randomized MOSAIC trial. Proc.Am.Soc.Clin.Oncol. 2003;22:253a (Abstr 1015).

21. Wolmark N, Wieand S, Kuebler JP, Colangelo L. A phase III trial comparing FULV to FULV+ oxaliplatin in stage II or III carcinoma of the colon: Results of NSABP protocol C-07. J.Clin. Oncol. 2005;23:246s (Abstr 3500).

22. Kuebler JP, Wieand HS, O'Connell MJ, Smith RE, Colangelo LH, Yothers G, et al. Oxaliplatin combined with weekly bolus fluorouracil and leucovorin as surgical adjuvant chemotherapy for stage II and III colon cancer: Results from NSABP C-07. J.Clin. Oncol. 2007 Jun 1;25(16):2198-204.

23. Grothey A, Sargent DJ. FOLFOX for stage II colon cancer? A commentary on the recent FDA approval of oxaliplatin for adjuvant therapy of stage III colon cancer. J.Clin.Oncol. 2005 May 20;23(15):3311-3.

24. Figueredo A, Germond C, Maroun J, Browman G, Walker Dilks C, Wong S. Adjuvant therapy for stage II colon cancer after complete resection. Provincial Gastrointestinal Disease Site Group. Cancer Prev.Control 1997 Dec;1(5):379-92.
25. Mamounas E, Wieand S, Wolmark N, Bear HD, Atkins JN, Song K, et al. Comparative efficacy of adjuvant chemotherapy in patients with Dukes' B versus Dukes' C colon cancer: Results from four National Surgical Adjuvant Breast and Bowel Project adjuvant studies (C-01, C-02, C-03, and C-04). J.Clin.Oncol. 1999 May;17(5):1349-55.

26. Efficacy of adjuvant fluorouracil and folinic acid in B2 colon cancer. International Multicentre Pooled Analysis of B2 Colon Cancer Trials (IMPACT B2) Investigators. J.Clin.Oncol. 1999 May;17(5):1356-63.

27. Sargent DJ, Wieand HS, Haller DG, Gray R, Benedetti JK, Buyse $\mathrm{M}$, et al. Disease-free survival versus overall survival as a primary end point for adjuvant colon cancer studies: Individual patient data from 20,898 patients on 18 randomized trials. J.Clin.Oncol. 2005 Dec 1;23(34):8664-70.

28. Sargent DJ, Patiyil S, Yothers G, Haller DG, Gray R, Benedetti J, et al. End points for colon cancer adjuvant trials: Observations and recommendations based on individual patient data from 20,898 patients enrolled onto 18 randomized trials from the ACCENT Group. J.Clin.Oncol. 2007 Oct 10;25(29):4569-74.

29. De Gramont A, Boni C, Navarro M, Tabernero J, Hickish T, Topham $\mathrm{C}$, et al. Oxaliplatin/5FU/LV in adjuvant colon cancer: Updated efficacy results of the MOSAIC trial, including survival, with a median follow-up of six years. J.Clin.Oncol. 2007;25:18S (Abstract) 